\title{
FLUXOS DE ÓXIDO NITROSO NA INTERFACE AR-MAR NA BAÍA DE GUANABARA
}

Giselle Parno Guimarães e William Zamboni de Mello*

Departamento de Geoquímica, Instituto de Química, Universidade Federal Fluminense, Outeiro de São João Batista, s/n, 24020-007 Niterói - RJ, Brasil

Recebido em 23/5/07; aceito em 11/4/08; publicado na web em 24/9/08

NITROUS OXIDE FLUXES AT THE AIR-SEA INTERFACE IN GUANABARA BAY. In Surface water concentrations of $\mathrm{N}_{2} \mathrm{O}$ were measured at 37 stations in Guanabara Bay and fluxes estimated across the air-sea interface. Concentrations averaged $8.2 \pm 2.2$ $\mathrm{nmol} \mathrm{L} \mathrm{L}^{-1}$ and $90 \%$ of the stations showed supersaturation averaging $33 \% . \mathrm{N}_{2} \mathrm{O}$ fluxes were estimated using a two-film model which is given by the product of the concentration difference across the film and the gas transfer coefficient $\left(k_{\mathrm{w}}\right)$. Two parametrizations of $k_{\mathrm{w}}$ were used which provided average fluxes of 0.3 and $3.0 \mu \mathrm{g} \mathrm{N} \mathrm{m}^{-2} \mathrm{~h}^{-1}$. Flux measurements using floating chambers (not reported here) seem to agree with the upper limit of these estimates.

Keywords: nitrous oxide; air-sea exchange; Guanabara Bay.

\section{INTRODUÇÃO}

$\mathrm{O}$ óxido nitroso $\left(\mathrm{N}_{2} \mathrm{O}\right)$ é o segundo composto de nitrogênio $(\mathrm{N})$ mais abundante na atmosfera terrestre e origina-se de fontes naturais e antrópicas. $\mathrm{O} \mathrm{N}_{2} \mathrm{O}$ exerce importante papel no controle do ozônio $\left(\mathrm{O}_{3}\right)$ estratosférico bem como na temperatura da superfície do planeta. Por ser a principal fonte estratosférica de óxido nítrico $\left[\mathrm{N}_{2} \mathrm{O}+\mathrm{O}\left({ }^{1} \mathrm{D}\right)\right.$ $\rightarrow 2 \mathrm{NO}$ ], o $\mathrm{N}_{2} \mathrm{O}$ contribui de forma indireta para o consumo do $\mathrm{O}_{3}$ estratosférico $\left[\mathrm{NO}+\mathrm{O}_{3} \rightarrow \mathrm{NO}_{2}+\mathrm{O}_{2}\right.$ ], que protege a superfície do planeta de uma maior incidência de radiação ultravioleta. Na troposfera, $\mathrm{o} \mathrm{N}_{2} \mathrm{O}$ absorve a radiação infravermelha emitida pela superfície da Terra e é responsável por 5-6\% do efeito estufa. ${ }^{1}$

Por ser um gás pouco reativo na troposfera, o $\mathrm{N}_{2} \mathrm{O}$ possui um tempo de vida de aproximadamente 125 anos, que é o quociente da razão entre sua massa total na atmosfera $[\sim 1500 \mathrm{Tg} \mathrm{N}(1 \mathrm{Tg}=$ 1 teragrama $\left.=10^{12} \mathrm{~g}\right)$ ] e sua taxa de consumo global na atmosfera $\left(\sim 12 \mathrm{Tg} \mathrm{N}\right.$ ano $\left.^{-1}\right) .^{2}$ De meados do século XVIII até 2003, a concentração (fração molar) de $\mathrm{N}_{2} \mathrm{O}$ na atmosfera superficial cresceu $17 \%$, isto é, de 270 a $317 \mathrm{ppb}^{2,3}$ (parte por bilhão, ppb $=10^{-9} ; 1 \mathrm{ppb}$ de $\mathrm{N}_{2} \mathrm{O}=1,80 \mu \mathrm{g} \mathrm{N} \mathrm{O} \mathrm{m}^{-3}$, para $T=25^{\circ} \mathrm{C}$ e $P=1 \mathrm{~atm}$ ). Nos últimos 25 anos, esse crescimento tem sido linear e de $0,8 \mathrm{ppb}^{-1} \mathrm{ano}^{-1}(0,25 \%$ $\mathrm{ano}^{-1}$ ), representando um acúmulo anual da ordem de $4 \mathrm{Tg} \mathrm{N}$. Este crescimento é atribuído principalmente às atividades agropecuárias, a alguns processos industriais e às queimadas. ${ }^{3,4}$ Aproximadamente metade do total global de $\mathrm{N}_{2} \mathrm{O}$ emitido para a atmosfera origina-se de fontes antrópicas. ${ }^{2}$

$\mathrm{Na}$ natureza, o $\mathrm{N}_{2} \mathrm{O}$ é produzido por processos microbiológicos de nitrificação e desnitrificação em sistemas continentais e marinhos (solo, água e sedimentos). A nitrificação, definida como a oxidação biológica do amônio $\left(\mathrm{NH}_{4}^{+}\right)$a nitrato $\left(\mathrm{NO}_{3}^{-}\right)$, é conduzida predominantemente por bactérias quimioautotróficas que obtêm energia da oxidação do $\mathrm{NH}_{4}^{+}$a nitrito $\left(\mathrm{NO}_{2}^{-}\right)$e do $\mathrm{NO}_{2}^{-}$a $\mathrm{NO}_{3}^{-}$para transformar dióxido de carbono $\left(\mathrm{CO}_{2}\right)$ em matéria orgânica. $\mathrm{O} \mathrm{N}_{2} \mathrm{O}$ é um subproduto da nitrificação na etapa de oxidação do $\mathrm{NH}_{4}^{+}$a $\mathrm{NO}_{2}^{-}:^{-5}$

$\mathrm{NH}_{4}^{+}+1 \frac{1 / 2}{\mathrm{O}_{2}} \rightarrow \mathrm{NO}_{2}^{-}+2 \mathrm{H}^{+}+\mathrm{H}_{2} \mathrm{O}$ (subproduto: $\mathrm{N}_{2} \mathrm{O}$ )

A bioquímica de produção de $\mathrm{N}_{2} \mathrm{O}$ via nitrificação ainda não é bem esclarecida, embora vários mecanismos tenham sido propostos. ${ }^{6}$

*e-mail: zamboni@geoq.uff.br
$\mathrm{Na}$ etapa da nitrificação em que o $\mathrm{NH}_{4}^{+}$é oxidado a $\mathrm{NO}_{2}{ }^{-}$a hidroxilamina $\left(\mathrm{NH}_{2} \mathrm{OH}\right)$ se forma como produto intermediário e o $\mathrm{N}_{2} \mathrm{O}$ pode se formar a partir de sua decomposição. Wrage et al. ${ }^{6}$ apresentam uma súmula dos mecanismos de produção de $\mathrm{N}_{2} \mathrm{O}$ via nitrificação e desnitrificação.

A desnitrificação ocorre em ambiente estritamente anaeróbio. As bactérias desnitrificadoras oxidam substâncias orgânicas (fontes de energia) e utilizam os íons $\mathrm{NO}_{3}^{-}$ou $\mathrm{NO}_{2}$ - como receptores de elétrons, que são reduzidos às formas gasosas de $\mathrm{N}_{2} \mathrm{O}$ ou nitrogênio diatômico $\left(\mathrm{N}_{2}\right)$, como exemplificado pela redução do $\mathrm{NO}_{2}^{-}$a $\mathrm{N}_{2} \mathrm{O}$ :

$\mathrm{CH}_{2} \mathrm{O}+2 \mathrm{NO}_{2}^{-}+2 \mathrm{H}^{+} \rightarrow \mathrm{CO}_{2}+\mathrm{N}_{2} \mathrm{O}+2 \mathrm{H}_{2} \mathrm{O}$

A desnitrificação pode tanto produzir quanto consumir $\mathrm{N}_{2} \mathrm{O}$. Nesse último caso ele é utilizado como receptor de elétrons e reduzido a $\mathrm{N}_{2}$ :

$\mathrm{CH}_{2} \mathrm{O}+2 \mathrm{~N}_{2} \mathrm{O} \rightarrow \mathrm{CO}_{2}+2 \mathrm{~N}_{2}+\mathrm{H}_{2} \mathrm{O}$

A eutrofização de sistemas aquáticos provoca aumento na produção de $\mathrm{N}_{2} \mathrm{O}$. ${ }^{7}$ Seitzinger e Kroeze ${ }^{8}$ estimaram para 1990 uma emissão global de $\mathrm{N}_{2} \mathrm{O}$ de rios, estuários e plataformas continentais da ordem de $1,9(0,9-9,0) \mathrm{Tg} \mathrm{N}$ ano ${ }^{-1}$, dos quais cerca de $90 \%$ foram atribuídos às atividades antrópicas, destacando-se o uso de fertilizantes, mas também o aporte atmosférico e a descarga de esgotos. A contribuição desses sistemas representa aproximada mente $25 \%$ da emissão global de $\mathrm{N}_{2} \mathrm{O}$ atribuída às atividades antrópicas. ${ }^{2}$ Seitzinger e Kroeze ${ }^{8}$ prevêem para meados do século XXI um incremento na emissão global de $\mathrm{N}_{2} \mathrm{O}$ de rios, estuários e plataformas continentais, em relação a 1990, que atingiria aproximadamente 4,9 $(1,3-13,0) \mathrm{Tg}$ $\mathrm{N}$ ano ${ }^{-1}$. Deve-se ressaltar que a maior parte dos estudos relacionados às emissões de $\mathrm{N}_{2} \mathrm{O}$ em sistemas aquáticos costeiros e marinhos expressivamente influenciados por atividades humanas ocorrem no Hemisfério Norte.

No Brasil, se desconhece qualquer estudo relacionado à emissão de gases de $\mathrm{N}\left(\mathrm{NH}_{3}\right.$ e $\left.\mathrm{N}_{2} \mathrm{O}\right)$ em sistemas aquáticos costeiros eutrofizados excetuando-se o recentemente publicado por Guimarães e de Mello, ${ }^{9}$ que apresenta uma estimativa das emissões de $\mathrm{NH}_{3}$ das águas da Baía de Guanabara. Face à grande carga de $\mathrm{N}$ orgânico lançada diariamente na Baía de Guanabara ${ }^{10}$ e aos elevados níveis de nitrogênio amoniacal $\left(\mathrm{NH}_{\mathrm{x}}\right)$ verificados nestas águas ${ }^{9,11}$ é de se 
esperar também concentrações elevadas de $\mathrm{N}_{2} \mathrm{O}$ em relação às águas da plataforma continental. O presente estudo, uma complementação àquele de Guimarães e de Mello, ${ }^{9}$ teve como objetivo estimar os fluxos de $\mathrm{N}_{2} \mathrm{O}$ na interface ar-mar na Baía de Guanabara, conhecer sua variação espacial e aventar sobre seus processos de produção nas águas superficiais da baía.

\section{PARTE EXPERIMENTAL}

\section{Área de estudo}

A Baía de Guanabara possui $384 \mathrm{~km}^{2}$ de área superficial total e $328 \mathrm{~km}^{2}$ de espelho d'água, descontadas as áreas de suas 42 ilhas. ${ }^{12}$ Atualmente a baía é reduzida em cerca de $10 \%$ de sua área original devido a aterros. A sua bacia de drenagem $\left(4080 \mathrm{~km}^{2}\right)$, posicionada entre o Atlântico e a Serra do Mar, abrange total ou parcialmente 15 municípios, englobando grande parte da Região Metropolitana do Rio de Janeiro. ${ }^{13}$ Dos 45 rios e canais que compõem a bacia de drenagem da baía, 6 são responsáveis por $85 \%$ da descarga fluvial total, estimada em $100 \mathrm{~m}^{3} \mathrm{~s}^{-1} \cdot{ }^{12} \mathrm{~A}$ descarga fluvial total apresenta variação sazonal significativa, cujas médias mensais estimadas variam de $33 \mathrm{~m}^{3} \mathrm{~s}^{-1}$ (julho) a $186 \mathrm{~m}^{3} \mathrm{~s}^{-1}$ (janeiro). ${ }^{12}$ Em abril, mês em que se realizou o presente estudo, a descarga fluvial média estimada é de aproximadamente $115 \mathrm{~m}^{3} \mathrm{~s}^{-1}{ }^{12}$

A Baía de Guanabara possui batimetria complexa, descrita por Amador. ${ }^{14} \mathrm{O}$ canal central, que se estende da entrada da baía até a Ilha de Paquetá, possui uma largura mediana de $400 \mathrm{~m}$ e profundidade média de $30 \mathrm{~m}$. Os trechos noroeste, norte e nordeste (APA de Guapimirim) são bastante rasos. A profundidade média ponderada pela área da baía é de $5,7 \mathrm{~m}$.

\section{Coletas e tratamento de amostras}

A coleta de amostras compreendeu 37 estações e ocorreu no período de 5 a 7 de abril de 2004. A distribuição das estações de amostragem, as trajetórias realizadas por data de coleta e a descrição dos procedimentos adotados para coleta de amostras de água, bem como das medições de $\mathrm{pH}$, condutividade e temperatura realizadas in situ, encontram-se em Guimarães e de Mello. ${ }^{9}$

Amostras de ar atmosférico foram coletadas somente em 6 das 37 estações de amostragem para quantificação de $\mathrm{N}_{2} \mathrm{O}$ na água. Para isso, aproximadamente $20 \mathrm{~mL}$ de ar atmosférico foram coletados e armazenados em seringas (Embramac) de polipropileno de $60 \mathrm{~mL}$ vedadas por meio de torneiras plásticas de 3 vias.

Para extração e posterior determinação da concentração de $\mathrm{N}_{2} \mathrm{O}$ na água do mar, adotou-se a técnica do equilíbrio em headspace. $\mathrm{Na}$ estação de amostragem, um volume ligeiramente superior a $30 \mathrm{~mL}$ de amostra de água foi transferido diretamente da garrafa de van Dorn, por meio de uma mangueira de borracha, para uma seringa do mesmo tipo da utilizada para coleta de ar atmosférico. Esta transferência foi feita cuidadosamente, evitando-se a formação de bolhas de ar na amostra de água na seringa. Logo em seguida, o volume de amostra de água foi reduzido a $30 \mathrm{~mL}$ e a seringa preenchida com igual volume de ar atmosférico. A seringa foi então imediatamente submetida a 50 agitações manuais e, após este procedimento, o ar contido no headspace foi transferido para outra seringa (seca) de 60 $\mathrm{mL}$ através do acoplamento das torneiras de 3 vias das duas seringas. Este procedimento foi efetuado para evitar o risco de transferência de água do mar ao sistema analítico, podendo resultar em prejuízo às determinações de $\mathrm{N}_{2} \mathrm{O}$ e danos à coluna cromatográfica. As seringas, contendo amostras de ar atmosférico e de ar do headspace (resultante da extração), foram então conduzidas ao laboratório e analisadas em menos de $24 \mathrm{~h}$.
A concentração de $\mathrm{N}_{2} \mathrm{O}$ na água do mar $\left(c_{\text {mar }} ;\right.$ em nmol L-1 $)$ foi calculada através da Equação 4:

$c_{\text {mar }}=\left[K_{0} \times c_{\mathrm{hs}(\mathrm{f})}\right]+\left[(P / R T) \times\left(c_{\mathrm{hs}(\mathrm{f})}-c_{\mathrm{hs}(\mathrm{i})}\right)\right]$

onde $c_{\mathrm{hs}(\mathrm{f})}$ e $c_{\mathrm{hs}(\mathrm{i})}$ são, respectivamente, as concentrações de $\mathrm{N}_{2} \mathrm{O}$ (em $\mathrm{ppb})$ final e inicial no headspace da seringa [Obs.: $c_{\mathrm{hs}(\mathrm{i})}$ representa a concentração de $\mathrm{N}_{2} \mathrm{O}$ no ar ambiente, portanto, $c_{\mathrm{hs}(\mathrm{i})}=c_{\mathrm{ar}}$ (Equação 11)], $K_{0}$ é o coeficiente de solubilidade do $\mathrm{N}_{2} \mathrm{O}^{15}$ calculado para a temperatura e salinidade da água do mar in situ e pressão de 1 atm (Equação 11), $P$ é a pressão (assume-se $1 \mathrm{~atm}), R$ é a constante universal dos gases $(0,082$ $\mathrm{L}$ atm K $\left.\mathrm{K}^{-1} \mathrm{~mol}^{-1}\right)$ e $T$ (em K) é a temperatura da água do mar in situ.

No laboratório, alíquotas das amostras de água do mar foram filtradas, no mesmo dia da coleta, através de membranas de fibra de vidro de aproximadamente $0,7 \mu \mathrm{m}$ de diâmetro de poro (Sartorius ${ }^{\circledR}$ ). Após filtragem, uma parcela do volume filtrado de cada amostra foi destinada à determinação (no mesmo dia) de $\mathrm{NO}_{2}^{-}$e uma outra foi imediatamente estocada em freezer (a aproximadamente $-22^{\circ} \mathrm{C}$ ) para posterior determinação de $\mathrm{NO}_{3}$.

\section{Análises químicas}

Nas amostras de água do mar foram efetuadas as análises de nitrogênio amoniacal $\left(\mathrm{NH}_{x}\right)$, nitrito $\left(\mathrm{NO}_{2}^{-}\right)$e nitrato $\left(\mathrm{NO}_{3}^{-}\right)$. As especificidades do procedimento para determinação de $\mathrm{NH}_{x}$ encontramse detalhadamente descritas em Guimarães e de Mello. ${ }^{9} \mathrm{O} \mathrm{NO}_{2}^{-}$foi determinado pelo método do acoplamento da sulfanilamida diazotada com o dicloridrato de $N$-1-nafitiletilenodiamina, com absorbância medida a $525 \mathrm{~nm} \cdot{ }^{16} \mathrm{O} \mathrm{NO}_{3}^{-}$foi determinado após redução a $\mathrm{NO}_{2}{ }^{-} \mathrm{em}$ coluna redutora de cádmio e subtração da concentração inicial de $\mathrm{NO}_{2}{ }^{-16,17}$ As medidas de absorbância de amostras e padrões foram realizadas em um espectrofotômetro Hitachi modelo U-1100. Os limites de detecção foram de $0,1 \mu \mathrm{mol} \mathrm{L} \mathrm{L}^{-1}$ para $\mathrm{NO}_{2}^{-}$e $\mathrm{NO}_{3}^{-}$. As precisões analíticas das determinações de $\mathrm{NO}_{2}{ }^{-}$e $\mathrm{NO}_{3}^{-}$realizadas em triplicata estiveram nas faixas de $\pm 7 \%$.

$\mathrm{O} \mathrm{N}_{2} \mathrm{O}$, nas amostras de ar atmosférico e do headspace resultante das extrações das amostras de água, foi analisado em um cromatógrafo a gás (CG) Shimadzu modelo GC-17A, equipado com detector de captura de elétrons de $\mathrm{Ni}^{63}$ operado a $340{ }^{\circ} \mathrm{C}$. O gás de arraste utilizado, numa vazão de $30 \mathrm{~cm}^{3} \mathrm{~min}^{-1}$, é uma mistura de argônio com $5 \%$ de metano (White Martins, gases especiais). Primeiramente, as amostras de ar são injetadas em um loop de $2 \mathrm{~cm}^{3}$ acoplado a uma válvula de 6 vias em aço inoxidável, fixada na parte externa do forno do CG. Com a mudança de posição da alavanca da válvula, a amostra contida no loop é transferida diretamente à coluna cromatográfica, construída em tubo de aço inoxidável (comprimento $=3,2 \mathrm{~m}$; d.i. $=1 / 8$ ") e empacotada com Porapak Q (80-100 mesh), que é operada a $60^{\circ} \mathrm{C}$. A concentração de $\mathrm{N}_{2} \mathrm{O}$ na amostra foi determinada por comparação da área integrada do pico obtido da amostra com a área do pico de padrões analíticos de $\mathrm{N}_{2} \mathrm{O}$ diluídos em $\mathrm{N}_{2}$, cujas concentrações foram de 356 e 840 ppb (White Martins, gases especiais). As amostras foram analisadas de 3 a 15 $\mathrm{h}$ após as coletas ou extrações. A precisão analítica foi de $\pm 1 \%$, valor que representa o coeficiente de variação das áreas dos picos de 5 réplicas de cada um dos padrões.

\section{Cálculo do fluxo de óxido nitroso na interface ar-mar}

Liss e Slater ${ }^{18}$ descreveram um modelo no qual a transferência do gás é realizada através de duas microcamadas adjacentes (twolayer model) na interface ar-mar. Parte-se do princípio que ambos os fluidos (ar e mar) são considerados bem misturados e a resistência ao transporte em ambas as fases acontece em uma estreita camada, na 
qual a transferência é realizada por difusão molecular. Através deste modelo, o fluxo de $\mathrm{N}_{2} \mathrm{O}$ na interface ar-mar pode ser parametrizado como:

$F=k_{\mathrm{w}}\left(c_{\text {mar }}-c_{\text {eq,ar }}\right)$

onde $F$ é o fluxo do gás na interface ar-mar, $k_{\mathrm{w}}$ é a velocidade de transferência do gás na fase aquosa, $c_{\operatorname{mar}}$ é a concentração do gás medida na superfície da água do mar e $c_{\text {eq,ar }}$ é a concentração do gás calculada para a superfície da água do mar sob a condição de equilíbrio com sua concentração medida no ar. Neste caso, os valores de $F$ positivos denotam transferência do gás da superfície do mar para a atmosfera e o inverso para os valores de $F$ negativos.

A velocidade de transferência, $k_{w}$, é função de processos físicos na camada limite estagnada (stagnant boundary layer), da viscosidade cinemática da água $(v)$ e do coeficiente de difusão molecular do gás em água $(D) .{ }^{18-21}$ A razão entre os dois últimos termos representa o número de Schmidt $(S c=v / D)$, que é específico para cada gás e varia em função da temperatura $(S c$ decresce à medida que cresce a temperatura) e, em menor proporção, da salinidade. O Sc é adimensional, pois $v$ e $D$ expressam-se na mesma unidade, i.e., área tempo ${ }^{-1}$, em geral $\mathrm{cm}^{2} \mathrm{~s}^{-1}$.

A velocidade de transferência para gases com maior resistência na fase aquosa, tais como óxido nitroso $\left(\mathrm{N}_{2} \mathrm{O}\right)$, metano $\left(\mathrm{CH}_{4}\right)$ e sulfeto de dimetila $\left(\mathrm{CH}_{3} \mathrm{SCH}_{3}\right)$, e sua relação com a velocidade do vento, $u$, é discutida por Liss e Merlivat, ${ }^{20}$ que utilizaram resultados de vários estudos em túnel de vento para tentar especificar a relação entre $k_{\mathrm{w}}$ e $u$. Os estudos em túnel de vento mostram que a relação entre $k_{\mathrm{w}}$ e $u$ se ajusta a três equações lineares com distintos coeficientes angulares: ${ }^{20}$

$k_{\mathrm{w}}=0,17 u_{10}(S c / 600)^{-2 / 3}$ para $u_{10} \leq 3,6 \mathrm{~m} \mathrm{~s}^{-1}$

$k_{\mathrm{w}}=\left(2,85 u_{10}-9,65\right)(S c / 600)^{-1 / 2}$ para $3,6<u_{10} \leq 13 \mathrm{~m} \mathrm{~s}^{-1}$

$k_{\mathrm{w}}=\left(5,9 u_{10}-49,3\right)(S c / 600)^{-1 / 2}$ para $u_{10}>13 \mathrm{~m} \mathrm{~s}^{-1}$

onde $k_{\mathrm{w}}$ é a velocidade de transferência na fase aquosa $\left(\mathrm{cm} \mathrm{h}^{-1}\right)$ e $u_{10}$ é a velocidade do vento a $10 \mathrm{~m}$ de altura $\left(\mathrm{m} \mathrm{s}^{-1}\right)$.

Entretanto, em se tratando de águas de rios e estuários, alguns estudos utilizam diferentes parametrizações para o cálculo de $k_{\mathrm{w}}$, considerando que nesses sistemas a velocidade de transferência está sujeita não somente à turbulência provocada pelos ventos, ${ }^{19-21}$ mas também pelo movimento das marés. ${ }^{22,23}$ Raymond e Cole ${ }^{23}$ discutiram a aplicação de diferentes técnicas para a estimativa do fluxo de gases na interface ar-água em rios e estuários. Combinando resultados de vários estudos, cujos valores de $k_{\mathrm{w}}$ foram medidos por meio de câmaras flutuantes e traçadores (e.g., ${ }^{3} \mathrm{He},{ }^{222} \mathrm{Rn}$ e $\mathrm{SF}_{6}$,) para velocidades de vento na faixa de 0,2 a $6,5 \mathrm{~m} \mathrm{~s}^{-1}$, Raymond e Cole $\mathrm{e}^{23}$ propuseram a seguinte equação para o cálculo de fluxo de gases em sistemas fluviais e estuarinos:

$k_{\mathrm{w}}=1,91 \exp \left(0,35 u_{10}\right)(S c / 600)^{-1 / 2}$

No presente estudo, os fluxos de $\mathrm{N}_{2} \mathrm{O}$ na interface ar-mar foram estimados com base nas equações propostas por Liss e Melivat ${ }^{20}$ para o cálculo de $k_{\mathrm{w}}$, as mesmas utilizadas por Hashimoto et al. ${ }^{24} \mathrm{e}$ Zhang et al. ${ }^{25}$ para estimativas de fluxos de $\mathrm{N}_{2} \mathrm{O}$ nas baías de Tóquio (Japão) e Jiaozhou (China), respectivamente, e na equação proposta por Raymond e Cole, ${ }^{23}$ aplicada por Harrison e Matson ${ }^{26}$ para determinação de fluxos de $\mathrm{N}_{2} \mathrm{O}$ na interface ar-água em rios do Valle del Yaqui (México).

O número 600 nas Equações 6-9 é o valor de referência do $S c$ para $\mathrm{CO}_{2}$ em água doce a temperatura de $20^{\circ} \mathrm{C}$. O valor do $S c$ para o $\mathrm{N}_{2} \mathrm{O}$ pode ser calculado através da Equação 10, proposta por Wanninkhof ${ }^{21}$ para água do mar, para $T$ em $\mathrm{K}$ :

$S c=2301,1-151,1 T+4,7364 T^{2}+0,057431 T^{3}$

A concentração de $\mathrm{N}_{2} \mathrm{O}$ na superfície da água do mar sob a condição de equilíbrio com a concentração de $\mathrm{N}_{2} \mathrm{O}$ no ar $\left(c_{\text {eq,ar }}\right.$; em mol $\mathrm{L}^{-1}$ ) é calculada pela Equação 11:

$c_{\text {eq,ar }}=K_{0} \times c_{\text {ar }}$

onde $K_{0}$ representa o coeficiente de solubilidade do $\mathrm{N}_{2} \mathrm{O}\left(\mathrm{mol} \mathrm{L}^{-1}\right.$ $\mathrm{atm}^{-1}$ ) e $c_{\mathrm{ar}}$ é a concentração de $\mathrm{N}_{2} \mathrm{O}$ medida no ar expressa como pressão parcial do gás (atm). Neste caso, utilizou-se a função $K_{0}$, válida para a faixa de temperatura de $0 \mathrm{a} 40^{\circ} \mathrm{C}$, ajustada à condição de ar saturado em umidade e pressão total de $1 \mathrm{~atm}$, definida por Weiss e Price ${ }^{15}$ como:

$\ln K_{0}=\mathrm{A}_{1}+\mathrm{A}_{2}(100 / T)+\mathrm{A}_{3} \ln (T / 100)+\mathrm{A}_{4}(T / 100)^{2}+S\left[\mathrm{~B}_{1}+\mathrm{B}_{2}(T / 100)\right.$ $\left.+\mathrm{B}_{3}(T / 100)^{2}\right]$

onde $T$ é a temperatura (em K) e $S$ a salinidade (em ups). Os valores atribuídos às constantes são: ${ }^{15} \mathrm{~A}_{1}=-165,8806, \mathrm{~A}_{2}=222,8743, \mathrm{~A}_{3}$ $=92,0792, \mathrm{~A}_{4}=-1,48425, \mathrm{~B}_{1}=-0,056235, \mathrm{~B}_{2}=0,031619$ e $\mathrm{B}_{3}=$ $-0,0048472$. Para as possíveis faixas de temperatura e salinidade do ambiente estudado (i.e., águas da Baía de Guanabara), ${ }^{9}$ a temperatura exerce maior influência sobre a solubilidade do $\mathrm{N}_{2} \mathrm{O}$ do que a salinidade. Por exemplo, a $25{ }^{\circ} \mathrm{C}$, a solubilidade do $\mathrm{N}_{2} \mathrm{O}$ em água com $S=35$ ups é 7,3\% menor que para $S=20$ ups, ao passo que em água com $S=30$ ups, a solubilidade do $\mathrm{N}_{2} \mathrm{O}$ a $30^{\circ} \mathrm{C}$ é $26 \%$ menor que a $20^{\circ} \mathrm{C}$.

$\mathrm{O}$ grau de saturação do $\mathrm{N}_{2} \mathrm{O}$ na água $\left(\Delta \mathrm{N}_{2} \mathrm{O}\right.$; em \%) é calculado através da seguinte equação:

$\Delta \mathrm{N}_{2} \mathrm{O}=\left[\left(c_{\text {mar }} / c_{\text {eq,ar }}\right)-1\right] \times 100$

Valores positivos de $\Delta \mathrm{N}_{2} \mathrm{O}$ (supersaturação) sugerem produção do $\mathrm{N}_{2} \mathrm{O}$ na água, ao passo que valores negativos (subsaturação) sugerem consumo.

\section{RESULTADOS E DISCUSSÃO}

A Tabela 1 apresenta a estatística descritiva da temperatura, salinidade, $\mathrm{pH}$, nitrogênio amoniacal $\left(\mathrm{NH}_{\mathrm{x}}=\mathrm{NH}_{4}^{+}+\mathrm{NH}_{3}\right)$, nitrito $\left(\mathrm{NO}_{2}^{-}\right)$, nitrato $\left(\mathrm{NO}_{3}^{-}\right)$e óxido nitroso $\left(\mathrm{N}_{2} \mathrm{O}\right)$, medidos no período compreendido de 5 a 7 de abril de 2004 em amostras de águas superficiais obtidas de 37 estações de amostragem distribuídas pela Baía de Guanabara. A distribuição das concentrações de $\mathrm{NH}_{\mathrm{x}}$ nas águas superficiais da Baía de Guanabara e as estimativas de fluxos de $\mathrm{NH}_{3}$ na interface ar-mar, referentes a esta mesma campanha, foram apresentadas por Guimarães e de Mello. ${ }^{9}$

\section{Distribuição das concentrações de óxido nitroso}

Para o cálculo de $c_{\text {eq,arr }}$, variável independente nas Equações 5 e 13, utilizou-se como concentração de $\mathrm{N}_{2} \mathrm{O}$ no ar $\left(c_{\mathrm{ar}}\right)$ (Equação 11) o valor 325 ppb, que é a média aritmética das concentrações de $\mathrm{N}_{2} \mathrm{O}$ determinadas em algumas poucas amostras de ar $(n=6)$ coletadas durante os 3 dias de campanha. Apesar do pequeno número de determinações, este valor concorda com a concentração média de $\mathrm{N}_{2} \mathrm{O}$ no ar (326 $\pm 6 \mathrm{ppb} ; n=50)$, resultante de medições semanais realizadas no período de outubro de 2004 a outubro de 2005 no Instituto de Química da UFF. ${ }^{27}$ 
Tabela 1. Estatística descritiva dos parâmetros físico-químicos analisados em águas superficiais das 37 estações amostradas na baía de Guanabara no período de 5 a 7 de abril de 2004

\begin{tabular}{lccccccc}
\hline & Temperatura* & Salinidade* & $\mathrm{pH}^{*}$ & $\mathrm{NH}_{\mathrm{x}}^{*}$ & $\mathrm{NO}_{2}^{-}$ & $\mathrm{NO}_{3}^{-}$ & $\mathrm{N}_{2} \mathrm{O}^{-}$ \\
\hline Média aritmética & 27,6 & 30,8 & 8,52 & 26,2 & 0,67 & 0,88 & 8,2 \\
Desvio padrão & 1,1 & 2,9 & 0,18 & 38,7 & 0,54 & 0,46 & 2,2 \\
Mediana & 27,8 & 30,0 & 8,50 & 8,7 & 0,48 & 0,84 & 7,5 \\
Mínimo & 25,0 & 25,8 & 8,02 & 2,3 & 0,04 & 0,08 & 5,3 \\
Máximo & 29,6 & 35,2 & 8,85 & 143,2 & 2,07 & 1,82 & 15,1 \\
\hline
\end{tabular}

*ref. 9; temperatura em ${ }^{\circ} \mathrm{C}$; salinidade em ups; $\mathrm{NH}_{x}, \mathrm{NO}_{2}^{-}$e $\mathrm{NO}_{3}^{-}$em $\mu \mathrm{mol} \mathrm{L}{ }^{-1}$ e $\mathrm{N}_{2} \mathrm{O}$ em nmol L-1.

As concentrações de $\mathrm{N}_{2} \mathrm{O}$ nas águas superficiais da Baía de Guanabara variaram de 5,3 a $15 \mathrm{nmol} \mathrm{L}^{-1}$ (Tabela 1 ), cerca de três ordens de grandeza inferiores às encontradas para o $\mathrm{NH}_{\mathrm{x}}\left(2-143 \mu \mathrm{mol} \mathrm{L} \mathrm{L}^{-1}\right)$ no mesmo período. ${ }^{9}$ As águas superficiais da Baía de Guanabara apresentaram concentrações de $\mathrm{N}_{2} \mathrm{O}$ que variaram de condições de subsaturação $\left(\Delta \mathrm{N}_{2} \mathrm{O}<0\right)$ a supersaturação $\left(\Delta \mathrm{N}_{2} \mathrm{O}>0\right)$ em relação às concentrações sob a condição de equilíbrio com a concentração de $\mathrm{N}_{2} \mathrm{O}$ na atmosfera (325 ppb) (Tabela 2). Contudo, condições de supersaturação $\left(\Delta \mathrm{N}_{2} \mathrm{O}=\right.$ $6-147 \% ; n=33)$ prevaleceram em relação às de subsaturação $\left(\Delta \mathrm{N}_{2} \mathrm{O}=\right.$ $-14--3 \% ; n=3)$. O $\Delta \mathrm{N}_{2} \mathrm{O}$ médio da Baía foi $33 \%$, superior ao $\Delta \mathrm{N}_{2} \mathrm{O}$ médio observado em águas oceânicas $(4 \%) .{ }^{28}$ As altas concentrações de $\mathrm{N}_{2} \mathrm{O}$ nas águas superficiais da Baía estão relacionadas à elevada carga de esgoto doméstico recebida, em especial no setor oeste.

Condições de supersaturação de $\mathrm{N}_{2} \mathrm{O}$ superiores às encontradas na Baía de Guanabara foram relatadas por Hashimoto et al. ${ }^{24}$ para as águas da Baía de Tóquio $\left(\Delta \mathrm{N}_{2} \mathrm{O}=16-1530 \%\right)$, que foram atribuídas à grande descarga de efluentes de esgoto doméstico após tratamento aeróbico. Amostras de água coletadas no estágio final de uma única estação de tratamento na Baía de Tóquio, cuja vazão média era de 13,1 $\mathrm{m}^{3} \mathrm{~s}^{-1}$, apresentaram uma concentração média de $\mathrm{N}_{2} \mathrm{O}$ de $5,4 \mu \mathrm{mol} \mathrm{L} \mathrm{L}^{-1}$, resultando numa descarga diária de $\mathrm{N}_{2} \mathrm{O}$ para a baía de $170 \mathrm{~kg} \mathrm{~N} .^{24}$

A distribuição das concentrações de $\mathrm{N}_{2} \mathrm{O}$ nas águas superficiais da Baía de Guanabara é mostrada na Figura 1. As menores concentrações foram registradas em estações do canal central, enquanto que as maiores ocorreram nos arredores da Ilha do Governador, especialmente nas estações 17A e 18, localizadas respectivamente a sudeste e sul da ilha, onde os valores de $\Delta \mathrm{N}_{2} \mathrm{O}$ foram, respectivamente, $135 \mathrm{e}$ $147 \%$ (Tabela 2). Estas altas concentrações de $\mathrm{N}_{2} \mathrm{O}$ têm relação com

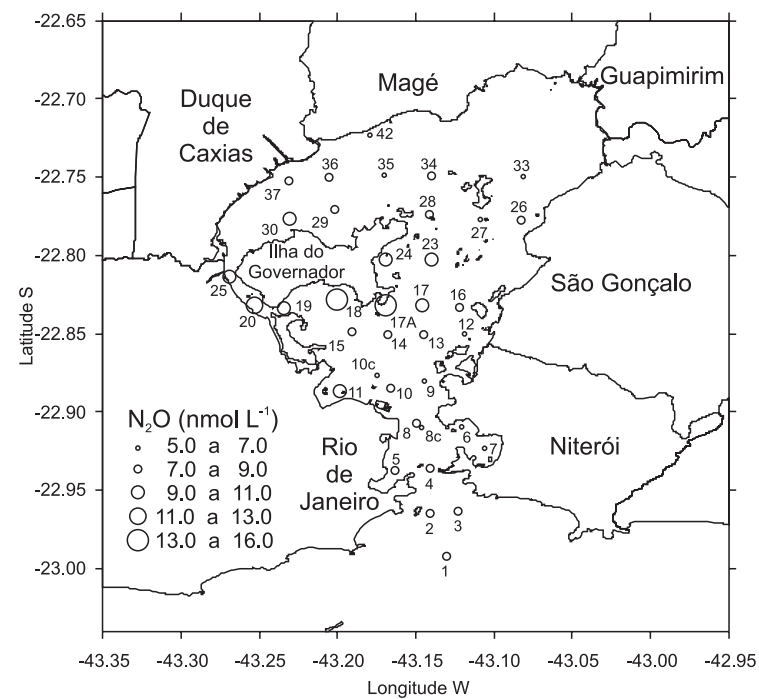

Figura 1. Distribuição espacial das concentrações de óxido nitroso $\left(\mathrm{N}_{2} \mathrm{O}\right)$ em águas superficiais nas 37 estações amostradas na Baía de Guanabara no período de 5 a 7 de abril de 2004 a maior descarga de esgotos domésticos neste trecho da Baía e, em decorrência disso, maior atividade microbiológica.

As concentrações da entrada da Baía de Guanabara (estações 1, 2 e 3) estiveram na faixa de 7,0 a 7,4 $\mathrm{nmol} \mathrm{L}^{-1}$, com valores de $\Delta \mathrm{N}_{2} \mathrm{O}$ na faixa de $13-27 \%$. Estes resultados encontram-se nas faixas verificadas por Morell et al. ${ }^{29}$ em águas superficiais do Oceano Atlântico ao norte e sul de Porto Rico, onde as concentrações de $\mathrm{N}_{2} \mathrm{O}$ variaram de 6,1 a $8,3 \mathrm{nmol} \mathrm{L}^{-1}\left(\Delta \mathrm{N}_{2} \mathrm{O} 4-44 \%\right)$. Já em águas superficiais do Atlântico equatorial entre a América do Sul e a África, Oudot et al..$^{30}$ encontraram um $\Delta \mathrm{N}_{2} \mathrm{O}$ médio de $8 \%$, com valores mais elevados nas margens continentais, em especial na africana, com valores de $\Delta \mathrm{N}_{2} \mathrm{O}$ de até $20 \%$.

\section{Distribuição das concentrações de nitrito e nitrato}

As menores concentrações de $\mathrm{NO}_{2}^{-}\left(<0,5 \mu \mathrm{mol} \mathrm{L}^{-1}\right)$ foram observadas principalmente em estações do canal central, enquanto valores mais elevados (> 1,5 $\left.\mu \mathrm{mol} \mathrm{L}^{-1}\right)$ ocorreram ao sul, sudeste e leste da Ilha do Governador (Figura 2). Ao sul da ponta do Jequiá (Ilha do Governador), na estação $17 \mathrm{~A}$, foi verificada a maior concentração $\left(2,1 \mu \mathrm{mol} \mathrm{L} \mathrm{L}^{-1}\right)$. A estação 18 , localizada a aproximadamente $1,5 \mathrm{~km}$ ao sul da Ponta de Santa Cruz (Ilha do Governador), e a estação 19, próxima à ponte de conexão entre a Ilha do Fundão e a Ilha do Governador, apresentaram valores de 2,0 e 1,5 $\mu \mathrm{mol} \mathrm{L} \mathrm{L}^{-1}$, respectivamente. Na estação 24 , a leste da

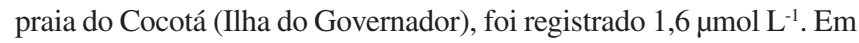
algumas estações a nordeste da Ilha do Governador e arredores da Ilha de Paquetá (estações 28, 33, 34 e 35) as concentrações de $\mathrm{NO}_{2}^{-}$foram menores que o limite de detecção $\left(0,1 \mu \mathrm{mol} \mathrm{L}^{-1}\right)$.

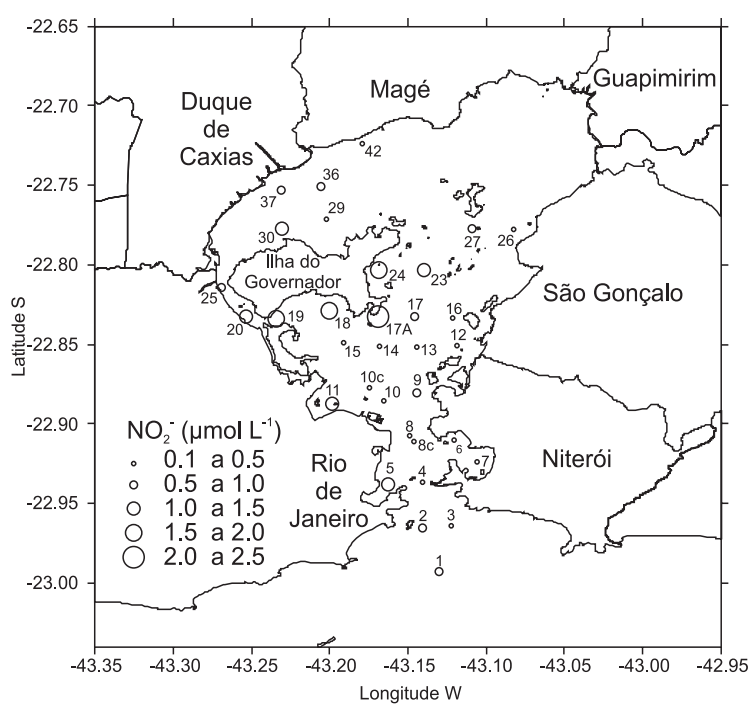

Figura 2. Distribuição espacial das concentrações de nitrito $\left(\mathrm{NO}_{2}^{-}\right)$em águas superficiais nas 37 estações amostradas na Baía de Guanabara no período de 5 a 7 de abril de 2004 
Tabela 2. Fluxos $(F)$ de $\mathrm{N}_{2} \mathrm{O}$ na interface ar-mar nas 37 estações de amostragem na Baía de Guanabara no período de 5 a 7 de abril de 2004

\begin{tabular}{|c|c|c|c|c|c|c|c|c|c|}
\hline Data & Estação & $\begin{array}{c}c_{\operatorname{mar}} \\
\mathrm{nmol} \mathrm{L}\end{array}$ & $\begin{array}{c}c_{e q, a r} \\
\mathrm{nmol} \mathrm{L}\end{array}$ & $\begin{array}{c}\Delta \mathrm{N}_{2} \mathrm{O} \\
\%\end{array}$ & $\begin{array}{c}u_{10} \\
\mathrm{~m} \mathrm{~s}^{-1}\end{array}$ & \multicolumn{2}{|c|}{$\mathrm{cm} \mathrm{h}^{-1}$} & \multicolumn{2}{|c|}{$\mu \mathrm{g} \mathrm{N} \mathrm{m}^{-2} \mathrm{~h}^{-1}$} \\
\hline $07 / 4 / 04$ & 1 & 7,2 & 6,2 & 16 & 1,9 & 0,36 & 4,03 & 0,10 & 1,11 \\
\hline $07 / 4 / 04$ & 2 & 7,4 & 5,8 & 27 & 1,9 & 0,39 & 4,30 & 0,18 & 1,92 \\
\hline $07 / 4 / 04$ & 3 & 7,0 & 6,2 & 13 & 1,9 & 0,36 & 4,02 & 0,08 & 0,91 \\
\hline $07 / 4 / 04$ & 4 & 7,6 & 6,2 & 22 & 1,8 & 0,34 & 3,90 & 0,13 & 1,48 \\
\hline $07 / 4 / 04$ & 5 & 7,6 & 6,3 & 20 & 1,8 & 0,33 & 3,82 & 0,12 & 1,35 \\
\hline $07 / 4 / 04$ & 6 & 6,1 & 6,3 & -3 & 2,1 & 0,39 & 4,27 & $-0,02$ & $-0,20$ \\
\hline $07 / 4 / 04$ & 7 & 5,3 & 6,2 & -14 & 2,1 & 0,40 & 4,33 & $-0,10$ & $-1,03$ \\
\hline $05 / 4 / 04$ & 8 & 8,1 & 6,5 & 24 & 2,5 & 0,45 & 4,76 & 0,19 & 2,05 \\
\hline $07 / 4 / 04$ & $8 \mathrm{C}$ & 5,9 & 6,3 & -6 & 1,8 & 0,34 & 3,86 & $-0,04$ & $-0,41$ \\
\hline $05 / 4 / 04$ & 9 & 6,9 & 6,4 & 8 & 2,5 & 0,46 & 4,88 & 0,07 & 0,73 \\
\hline $05 / 4 / 04$ & 10 & 8,2 & 6,3 & 30 & 2,5 & 0,47 & 4,96 & 0,25 & 2,65 \\
\hline $07 / 4 / 04$ & $10 \mathrm{C}$ & 6,2 & 6,2 & 0 & 3,0 & 0,57 & 5,95 & 0,00 & $-0,02$ \\
\hline $07 / 4 / 04$ & 11 & 9,2 & 6,1 & 50 & 2,5 & 0,49 & 5,07 & 0,42 & 4,39 \\
\hline $05 / 4 / 04$ & 12 & 7,0 & 6,2 & 13 & 2,5 & 0,49 & 5,10 & 0,11 & 1,14 \\
\hline $05 / 4 / 04$ & 13 & 7,2 & 6,3 & 14 & 2,9 & 0,54 & 5,65 & 0,14 & 1,43 \\
\hline $05 / 4 / 04$ & 14 & 7,5 & 6,4 & 18 & 2,9 & 0,54 & 5,62 & 0,17 & 1,82 \\
\hline $05 / 4 / 04$ & 15 & 7,3 & 6,3 & 16 & 3,0 & 0,57 & 5,94 & 0,16 & 1,66 \\
\hline $05 / 4 / 04$ & 16 & 7,6 & 6,1 & 25 & 2,5 & 0,50 & 5,16 & 0,22 & 2,24 \\
\hline $05 / 4 / 04$ & 17 & 10,0 & 6,1 & 63 & 2,5 & 0,49 & 5,13 & 0,53 & 5,52 \\
\hline $05 / 4 / 04$ & $17 \mathrm{~A}$ & 14,4 & 6,1 & 135 & 3,2 & 0,63 & 6,55 & 1,46 & 15,2 \\
\hline $05 / 4 / 04$ & 18 & 15,1 & 6,1 & 147 & 3,2 & 0,64 & 6,59 & 1,60 & 16,5 \\
\hline $05 / 4 / 04$ & 19 & 10,5 & 6,2 & 69 & 2,7 & 0,53 & 5,50 & 0,64 & 6,61 \\
\hline $05 / 4 / 04$ & 20 & 12,7 & 6,2 & 105 & 2,7 & 0,53 & 5,49 & 0,97 & 9,97 \\
\hline $06 / 4 / 04$ & 23 & 9,3 & 6,3 & 46 & 2,4 & 0,46 & 4,84 & 0,38 & 3,97 \\
\hline $06 / 4 / 04$ & 24 & 10,2 & 6,2 & 64 & 2,5 & 0,48 & 5,04 & 0,53 & 5,58 \\
\hline $05 / 4 / 04$ & 25 & 9,2 & 6,1 & 50 & 2,7 & 0,55 & 5,59 & 0,47 & 4,78 \\
\hline $06 / 4 / 04$ & 26 & 7,0 & 6,1 & 16 & 2,0 & 0,41 & 4,41 & 0,11 & 1,19 \\
\hline $06 / 4 / 04$ & 27 & 7,0 & 6,1 & 15 & 2,5 & 0,51 & 5,26 & 0,13 & 1,37 \\
\hline $06 / 4 / 04$ & 28 & 7,1 & 6,1 & 17 & 2,5 & 0,50 & 5,17 & 0,15 & 1,50 \\
\hline $06 / 4 / 04$ & 29 & 8,2 & 6,0 & 37 & 2,1 & 0,43 & 4,56 & 0,27 & 2,86 \\
\hline $06 / 4 / 04$ & 30 & 9,0 & 6,2 & 45 & 2,1 & 0,41 & 4,46 & 0,33 & 3,51 \\
\hline $06 / 4 / 04$ & 33 & 6,5 & 6,0 & 9 & 2,0 & 0,42 & 4,51 & 0,06 & 0,67 \\
\hline $06 / 4 / 04$ & 34 & 7,2 & 6,1 & 18 & 2,4 & 0,48 & 5,03 & 0,15 & 1,57 \\
\hline $06 / 4 / 04$ & 35 & 6,6 & 5,9 & 12 & 2,4 & 0,50 & 5,14 & 0,10 & 1,00 \\
\hline 06/4/04 & 36 & 8,8 & 6,3 & 40 & 3,0 & 0,58 & 5,98 & 0,41 & 4,21 \\
\hline 06/4/04 & 37 & 8,6 & 6,1 & 40 & 3,0 & 0,60 & 6,14 & 0,41 & 4,24 \\
\hline 06/4/04 & 42 & 6,3 & 6,0 & 6 & 3,0 & 0,62 & 6,28 & 0,06 & 0,58 \\
\hline Média aritmética & & 8,2 & 6,2 & 33 & 2,5 & 0,48 & 5,06 & 0,30 & 3,08 \\
\hline Desvio padrão & & 2,2 & 0,1 & & 0,4 & 0,08 & 0,76 & 0,37 & 3,79 \\
\hline Mediana & & 7,5 & 6,2 & 20 & 2,5 & 0,49 & 5,07 & 0,16 & 1,66 \\
\hline Mínimo & & 5,3 & 5,8 & -14 & 1,8 & 0,33 & 3,82 & $-0,10$ & $-1,03$ \\
\hline Máximo & & 15,1 & 6,5 & 147 & 3,2 & 0,64 & 6,59 & 1,60 & 16,55 \\
\hline
\end{tabular}

$c_{\text {mar }}=$ concentração de $\mathrm{N}_{2} \mathrm{O}$ na água; $c_{\text {eq.ar }}=$ concentração de $\mathrm{N}_{2} \mathrm{O}$ na água em equilíbrio com a concentração no ar; $\Delta \mathrm{N}_{2} \mathrm{O}=$ grau de saturação de $\mathrm{N}_{2} \mathrm{O}$ na água; $u_{10}=$ velocidade do vento a $10 \mathrm{~m}$ de altura; $k_{\mathrm{w}}=$ velocidade de transferência.

As concentrações de $\mathrm{NO}_{3}$ - foram muito próximas às de $\mathrm{NO}_{2}^{-}$. Os maiores valores foram observados ao longo de toda a extensão do trecho a oeste do canal central e os litorais dos municípios do Rio de Janeiro e Duque de Caxias (Figura 3). Os valores mais baixos de $\mathrm{NO}_{3}{ }^{-}\left(\leq 0,5 \mu \mathrm{mol} \mathrm{L} \mathrm{L}^{-1}\right)$ ocorreram em estações ao norte da baía, no setor entre a praia de Mauá (município de Magé) e a Ilha de Paquetá, a nordeste da Ilha do Governador, e a oeste da praia de Itaóca, município de São Gonçalo (estações 25, 26, 28, 34, 35 e 42). Nas três estações localizadas fora da entrada da Baía de Guanabara, as concentrações de $\mathrm{NO}_{3}{ }^{-}$estiveram na faixa de 0,5 a $1,5 \mu \mathrm{mol} \mathrm{L}{ }^{-1}$.

Com base em monitoramentos realizados pela FEEMA (Fundação Estadual de Engenharia do Meio Ambiente) em 13 estações de amostragem durante o período de 1980 a 1993 , Kjerfve et al. ${ }^{12}$ relataram para as águas superficiais da Baía de Guanabara concentrações 


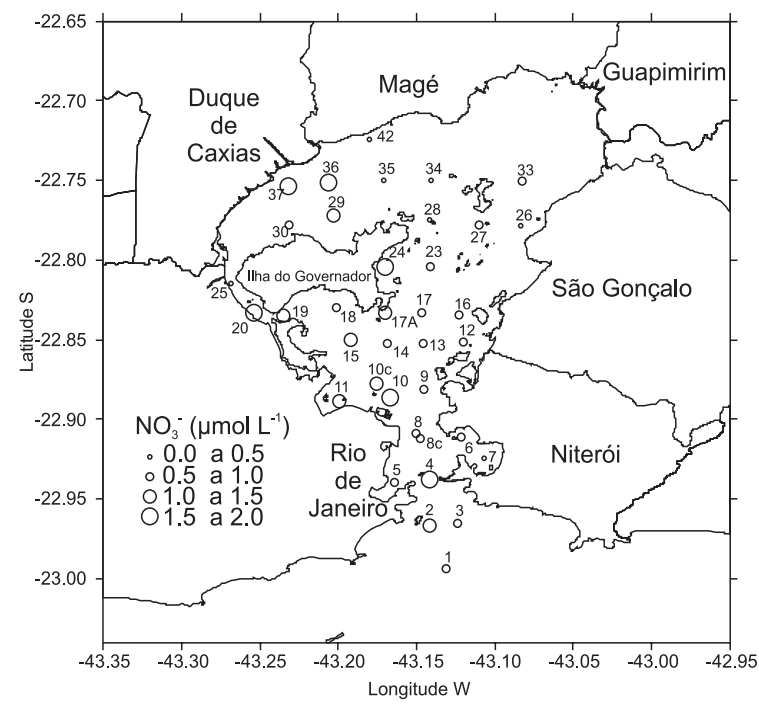

Figura 3. Distribuição espacial das concentrações de nitrato $\left(\mathrm{NO}_{3}^{-}\right)$em águas superficiais nas 37 estações amostradas na Baía de Guanabara no período de 5 a 7 de abril de 2004

médias de $\mathrm{NO}_{2}^{-}$na faixa de 0,2 $\pm 0,3$ a 2,6 $\pm 3,0 \mu \mathrm{mol} \mathrm{L}{ }^{-1}$ e $\mathrm{NO}_{3}^{-}$na faixa de $1,2 \pm 0,6$ a 5,2 $\pm 1,6 \mu \mathrm{mol} \mathrm{L}^{-1}$. Os valores de $\mathrm{NO}_{2}^{-}$medidos no presente estudo $\left(\leq 2,1 \mu \mathrm{mol} \mathrm{L^{-1 }}\right)$ (Tabela 1$)$ foram semelhantes àqueles citados por Kjerfve et al..$^{12}$, entretanto, os de $\mathrm{NO}_{3}^{-}(\leq 1,8 \mu \mathrm{M})$ estiveram próximos ao limite inferior citado por eles.

As concentrações de $\mathrm{N}_{2} \mathrm{O}$ nas águas superficiais da Baía de Guanabara apresentaram uma correlação clara e estatisticamente significativa com as concentrações de $\mathrm{NO}_{2}^{-}(\mathrm{r}=0,84$; $\mathrm{P}<0,01)(\mathrm{Fi}-$ gura $4 \mathrm{a}$ ), o que sugere que a produção do $\mathrm{N}_{2} \mathrm{O}$ neste ambiente possa estar associada predominantemente ao processo de nitrificação, do qual o $\mathrm{N}_{2} \mathrm{O}$ surge como subproduto na etapa de oxidação do $\mathrm{NH}_{4}^{+}$ a $\mathrm{NO}_{2}^{-}$(Equação 1). Menos evidentes, embora que estatisticamente significativas, foram as correlações entre $\mathrm{N}_{2} \mathrm{O}$ e $\mathrm{NO}_{3}{ }^{-}(\mathrm{r}=0,37 ; \mathrm{P}<$ 0,05) (Figura 4b) e $\mathrm{NH}_{\mathrm{x}}(\mathrm{r}=0,60 ; \mathrm{P}<0,01)$ (Figura 4c).

$\mathrm{Na}$ nitrificação, a produção de $\mathrm{N}_{2} \mathrm{O}$ depende da disponibilidade de $\mathrm{O}_{2}$. De acordo com dados compilados por Kjerfve et al. ${ }^{12}$ as águas superficiais da Baía de Guanabara são, em geral, supersaturadas em $\mathrm{O}_{2}$ dissolvido (concentração média $\sim 8,5 \mathrm{mg} \mathrm{L}^{-1} ; \Delta \mathrm{O}_{2} \sim 25 \%$ ), condições favoráveis ao processo de nitrificação. Experimentos laboratoriais, com culturas de bactérias nitrificadoras do gênero Nitrosomonas, mostram que a razão $\mathrm{N}_{2} \mathrm{O}_{2} \mathrm{NO}_{2}^{-}$, como resultado da oxidação do $\mathrm{NH}_{4}^{+}$, tende a aumentar com a redução da concentração de $\mathrm{O}_{2}$ no meio. ${ }^{31}$ Goreau et al. ${ }^{31}$ observaram um aumento de 0,003 a 0,1 na razão $\mathrm{N}_{2} \mathrm{O} / \mathrm{NO}_{2}{ }^{-}(\mathrm{mol} \mathrm{de} \mathrm{N} / \mathrm{mol}$ de $\mathrm{N})$ quando a concentração de $\mathrm{O}_{2}$ foi reduzida de 7 para $0,18 \mathrm{mg} \mathrm{L}^{-1}$. A razão $\mathrm{N}_{2} \mathrm{O} / \mathrm{NO}_{2}^{-}$média verificada nas águas superficiais da Baía de Guanabara foi de 0,02, valor intermediário a faixa encontrada por Goreau et al..${ }^{31}$ Apesar da dinâmica dos vários processos biogeoquímicos responsáveis pelas transformações das espécies nitrogenadas nas águas superficiais da Baía de Guanabara, a razão $\mathrm{N}_{2} \mathrm{O} / \mathrm{NO}_{2}$ - média corrobora a hipótese de que a nitrificação seja o principal processo formador do $\mathrm{N}_{2} \mathrm{O}$ nas águas superficiais da Baía.

\section{Fluxos de óxido nitroso}

Os fluxos de $\mathrm{N}_{2} \mathrm{O}$ na interface ar-mar da Baía de Guanabara, calculados individualmente para as 37 estações amostradas em abril de 2004, encontram-se compilados na Tabela 2. Os fluxos foram computados com base nas velocidades de transferência do gás $\left(k_{\mathrm{w}}\right)$ calculadas através das Equações propostas por Liss e Merlivat ${ }^{20}$
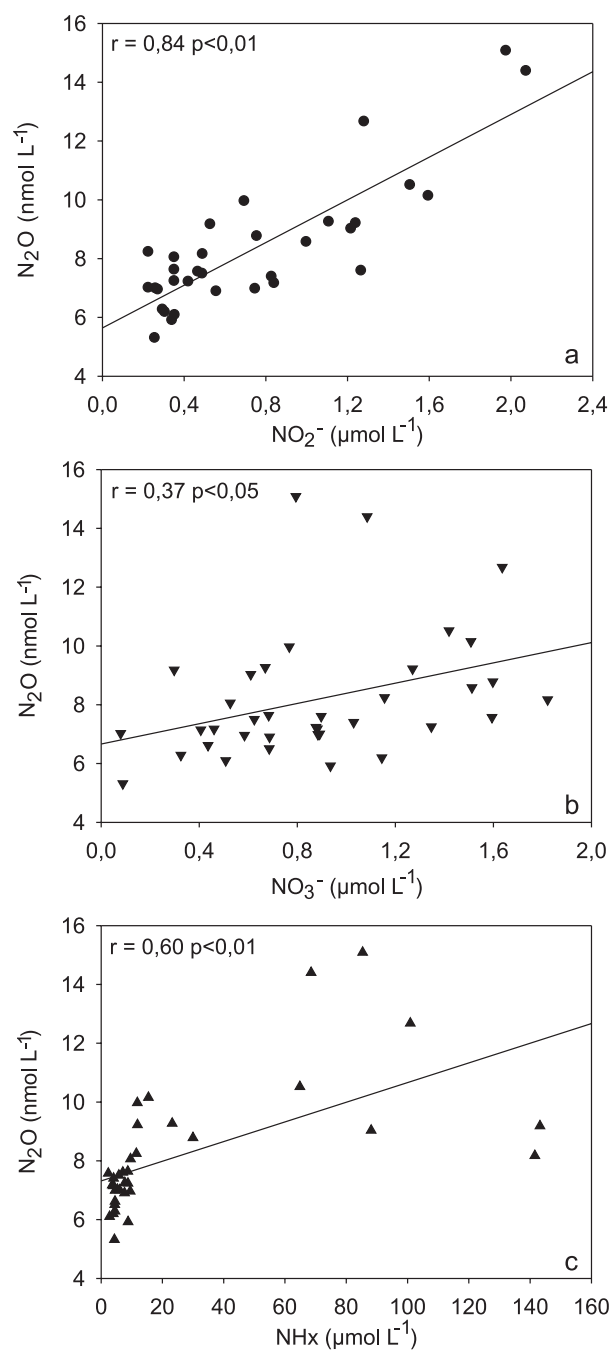

Figura 4. Relação óxido nitroso $\left(\mathrm{N}_{2} \mathrm{O}\right)$ vs. nitrito $\left(\mathrm{NO}_{2}^{-}\right)$, nitrato $\left(\mathrm{NO}_{3}^{-}\right)$e nitrogênio amoniacal $\left(\mathrm{NH}_{x}\right)$ no período de 5 a 7 de abril de 2004

(abrev. LM86) e Raymond e Cole ${ }^{23}$ (abrev. RC01). Para os cálculos de $k_{\mathrm{w}}$ foram utilizadas velocidades de vento medidas a aproximadamente $10 \mathrm{~m}$ acima da superfície do mar $\left(u_{10}\right)$ da estação meteorológica do campus do Gragoatá da UFF. Os valores de $u_{10}$ foram utilizados como média horária e corresponderam individualmente ao momento do dia em que cada amostra foi coletada. O período de coleta foi entre o início da manhã e o meio da tarde, período em que gradualmente o vento aumenta de intensidade, uma característica da brisa marítima. Nesse caso, as médias horárias de $u_{10}$ variaram de 1,8 a $3,2 \mathrm{~m} \mathrm{~s}^{-1}$ (Tabela 2). Sendo assim, aplicando-se LM86, os valores de $k_{\mathrm{w}}$ foram todos calculados através da Equação 6, que é a utilizada para vento cuja velocidade é inferior ou igual a $3,6 \mathrm{~m} \mathrm{~s}^{-1}$. Esses valores de $k_{\mathrm{w}}$ variaram de 0,33 a $0,64 \mathrm{~cm} \mathrm{~h}^{-1}$. Para a mesma faixa de $u_{10}$, os valores de $k_{\mathrm{w}}$ calculados com base na Equação 9 de RC01 variaram de 3,8 a $6,6 \mathrm{~cm} \mathrm{~h}^{-1}$. Esses valores encontram-se na faixa de $k_{\mathrm{w}}$ recomendada por Raymond e Cole $^{23}$ (i.e., 3-7 $\mathrm{cm} \mathrm{h}^{-1}$ ) como sendo aquela que expressa maior confiança nos resultados de fluxos de gases em rios e estuários calculados a partir da Equação 9.

As médias aritméticas ( \pm desvio padrão) dos fluxos de $\mathrm{N}_{2} \mathrm{O}$ foram $0,30 \pm 0,37 \mu \mathrm{g} \mathrm{N} \mathrm{m}^{-2} \mathrm{~h}^{-1}$, aplicando-se LM86, e 3,1 $\pm 3,8 \mu \mathrm{g} \mathrm{N} \mathrm{m}^{-2} \mathrm{~h}^{-1}$, aplicando-se RC01 (Tabela 2). As medianas foram, respectivamente, 0,16 e $1,7 \mu \mathrm{g} \mathrm{N} \mathrm{m}^{-2} \mathrm{~h}^{-1}$. A diferença entre os resultados é atribuída exclusivamente aos valores de $k_{\mathrm{w}}$ utilizados. LM86 considera que em lagos e oceanos $k_{\mathrm{w}}$ é influenciada pela turbulência provocada 
pela ação dos ventos, ao passo que RC01 considera no caso dos rios e estuários, além do vento, que $k_{\mathrm{w}}$ é influenciada também pela turbulência resultante do movimento das correntes. Com base nos valores médios encontrados na Baía de Guanabara para concentração de $\mathrm{N}_{2} \mathrm{O}$ na água $\left(c_{\text {mar }}=8,2 \mathrm{nmol} \mathrm{L}{ }^{-1}\right)$, concentração de $\mathrm{N}_{2} \mathrm{O}$ no $\operatorname{ar}\left(c_{\mathrm{ar}}\right.$ $=325 \mathrm{ppb})$, temperatura $\left(T=27,6{ }^{\circ} \mathrm{C}\right)$ e salinidade $(S=30,8 \mathrm{ups})$, a Figura 5 apresenta as variações do fluxo de $\mathrm{N}_{2} \mathrm{O}\left(F_{\mathrm{N} 2 \mathrm{O}}\right)$ em função da velocidade do vento, para a faixa de 0 a $10 \mathrm{~m} \mathrm{~s}^{-1}$, computadas a partir das Equações propostas por LM86 (Equações 6 e 7) e RC01 (Equação 9) para o cálculo de $k_{\mathrm{w}}$. Na Equação 9 (RC01), somente a velocidade do vento aparece como variável independente, a influência da turbulência devido à ação das marés encontra-se incorporada ao valor de sua constante. Isso se faz notar no valor de $F_{\mathrm{N} 2 \mathrm{O}}=1,2 \mu \mathrm{g} \mathrm{N}$ $\mathrm{m}^{-2} \mathrm{~h}^{-1}$ para a condição de ausência total de vento $\left(u_{10}=0\right)$ no caso da Equação 9 (RC01), ao passo que, sob essa mesma condição, $F_{\mathrm{N} 2 \mathrm{O}}$ $=0$ no caso da Equação 6 (LM86)

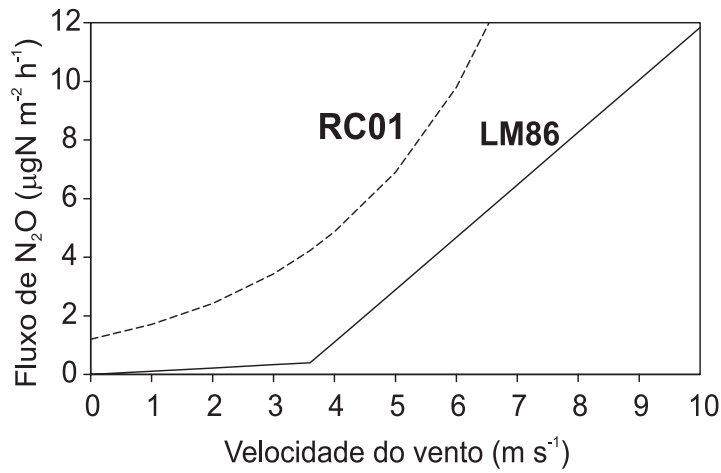

Figura 5. Curvas de variação do fluxo de $\mathrm{N}_{2} \mathrm{O}$ em função da velocidade do vento, entre 0 e $10 \mathrm{~m} \mathrm{~s}^{-1}$, computadas a partir das equações propostas por Liss e Merlivat ${ }^{20}$ (LM86) e Raymond e Cole ${ }^{23}$ (RC01), para $T=27,6^{\circ} \mathrm{C}, \mathrm{S}=$

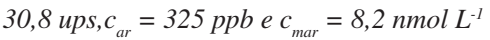

Os maiores fluxos de $\mathrm{N}_{2} \mathrm{O}$ foram obtidos para as estações $17 \mathrm{~A} \mathrm{e}$ 18 , situadas à sudeste da Ilha do Governador, em virtude desses locais terem apresentado as maiores concentrações de $\mathrm{N}_{2} \mathrm{O}$ (Figura 1). Do total de estações amostradas $(n=37)$, a maioria $(n=33)$ apresentou valores de fluxo positivos (i.e., $c_{\text {mar }}>c_{\text {eq.ar }}$; Equação 5), o que indica que a transferência de $\mathrm{N}_{2} \mathrm{O}$ ocorre predominantemente das águas superficiais da Baía para a atmosfera.

Apesar do $\Delta \mathrm{N}_{2} \mathrm{O}$ médio da Baía de Guanabara (33\%) ser maior que o $\Delta \mathrm{N}_{2} \mathrm{O}$ médio dos oceanos do mundo $(4 \%),{ }^{28}$ as emissões de $\mathrm{N}_{2} \mathrm{O}$ das águas da Baía se assemelham às emissões oceânicas $(0,4-$ $\left.2,2 \mu \mathrm{g} \mathrm{N} \mathrm{m}{ }^{-2} \mathrm{~h}^{-1}\right) .{ }^{28}$ Isso se explica em virtude da velocidade do vento exercer forte influência sobre $k_{\mathrm{w}}$ e esta sobre o fluxo na interface ar-mar. Por exemplo, em águas equatoriais do Atlântico, Oudot et $a l .{ }^{30}$ encontraram valores médios de $\Delta \mathrm{N}_{2} \mathrm{O}$ de $8 \%$ e de $u_{10}$ de $7,0 \mathrm{~m}$ $\mathrm{s}^{-1}$, e computaram fluxos de $\mathrm{N}_{2} \mathrm{O}\left(k_{\mathrm{w}}\right.$ de LM86) na faixa de 1,3 a 2,1 $\mu \mathrm{g} \mathrm{N} \mathrm{m}^{-2} \mathrm{~h}^{-1}$. Com base nos valores médios encontrados na Baía de Guanabara para $T, S, c_{\text {mar }}$ (Tabela 1) e $c_{\text {ar }}$ (325 ppb), os fluxos de $\mathrm{N}_{2} \mathrm{O}$ calculados a partir de $k_{\mathrm{w}}$ de LM86 para velocidades de vento de 2,5 e $5,0 \mathrm{~m} \mathrm{~s}^{-1}$ são, respectivamente, 0,3 e $2,9 \mu \mathrm{g} \mathrm{N} \mathrm{m} \mathrm{N}^{-2}$. Utilizando-se $k_{\mathrm{w}}$ de RC01 para as mesmas condições estabelecidas, os fluxos são, respectivamente, 2,9 e $6,9 \mu \mathrm{g} \mathrm{N} \mathrm{m}^{-2} \mathrm{~h}^{-1}$. Ressalta-se que a resposta de $k_{\mathrm{w}}$ de LM86 é mais acentuada para ventos com velocidade superior a 3,6 $\mathrm{m} \mathrm{s}^{-1}$ (Equação 7) que para aqueles com velocidade igual ou inferior a 3,6 $\mathrm{m} \mathrm{s}^{-1}$ (Equação 6).

Na Baía de Jiaozhou, utilizando $k_{\mathrm{w}}$ de LM86, ${ }^{20}$ Zhang et al. ${ }^{25}$ determinaram um fluxo médio de $\mathrm{N}_{2} \mathrm{O}$ de $10,8 \mu \mathrm{g} \mathrm{N} \mathrm{m}{ }^{-2} \mathrm{~h}^{-1}$. Esta baía possui algumas semelhanças geomorfológicas com a Baía de Guanabara e é subdividida em três sub-regiões distintas, de acordo com os impactos resultantes de atividades humanas e o regime de circulação de águas. Os fluxos elevados na Baía de Jiaozhou em relação aos computados para a Baía de Guanabara devem-se às maiores concentrações de $\mathrm{N}_{2} \mathrm{O}$ encontradas nas águas superficiais (4,7-84 $\left.\mathrm{nmol} \mathrm{L}^{-1}\right)$ e maiores velocidades dos ventos, cujos valores médios variaram de 4,7 a $6,2 \mathrm{~m} \mathrm{~s}^{-1}$. Na Baía de Tóquio, utilizando $k_{\mathrm{w}}$ de LM86, Hashimoto et al. ${ }^{24}$ computaram fluxos de $\mathrm{N}_{2} \mathrm{O}$ na faixa de 1,8 a $179 \mu \mathrm{g} \mathrm{N} \mathrm{m}^{-2} \mathrm{~h}^{-1}$, obtidos de concentrações de $\mathrm{N}_{2} \mathrm{O}$ na faixa de 8,8 a $139 \mathrm{nmol} \mathrm{L}^{-1}$ e uma velocidade do vento fixa de $5,0 \mathrm{~m} \mathrm{~s}^{-1}$. As velocidades do ventos utilizadas nos estudos de Zhang et al. ${ }^{25} \mathrm{e}$ Hashimoto et al. ${ }^{24}$ foram em média duas vezes maiores que a velocidade do vento média para os horários de coleta das amostras do presente estudo na Baía de Guanabara.

Utilizando-se os valores médios encontrados na Baía de Guanabara de concentração $T, S, c_{\operatorname{mar}}, u_{10}$ (Tabelas 1 e 2) e $c_{a r}$ (325 ppb), os fluxos de $\mathrm{N}_{2} \mathrm{O}$ computados a partir de $k_{\mathrm{w}}$ de LM86 e RC01 são, respectivamente, $0,3 \mathrm{e} 2,9 \mu \mathrm{g} \mathrm{N} \mathrm{m}^{-2} \mathrm{~h}^{-1}$. A partir desses valores estima-se uma taxa de emissão de $\mathrm{N}_{2} \mathrm{O}$ das águas da Baía (área $=328 \mathrm{~km}^{2}$ ) na faixa de 2 a $23 \mathrm{~kg} \mathrm{~N} \mathrm{dia}^{-1}$. Os fluxos de $\mathrm{N}_{2} \mathrm{O}$ computados a partir de $k_{\mathrm{w}}$ de RC01 para as estações situadas na costa sul da Ilha do Governador (17A, 1819 e 20) são bastante próximos aos medidos diretamente por meio de câmaras flutuantes por Couto ${ }^{27} \mathrm{em}$ local mais próximo à costa da Ilha do Governador, situado entre as estações 18 e 19. Entretanto, ressalta-se que a viabilidade de uso de câmaras flutuantes se limita às condições de águas sem ou com fracas ondulações, ou seja, condições de calmaria ou ventos fracos.

\section{CONCLUSÕES}

As concentrações de $\mathrm{N}_{2} \mathrm{O}$ nas águas superficiais da Baía de Guanabara variaram de 5,3 a $15 \mathrm{nmol} \mathrm{L}{ }^{-1}$, com média de 8,2 nmol $\mathrm{L}^{-1}$, correspondendo a uma condição de supersaturação média de $33 \%$, que é superior à verificada para as águas oceânicas $(4 \%) \cdot{ }^{28}$ As maiores concentrações ocorrem nas áreas mais poluídas por descarga de esgotos domésticos, apresentando forte correlação com as concentrações de $\mathrm{N}$ amoniacal e, principalmente, nitrito. Isso sugere que a nitrificação deva ser o principal processo formador do gás nas águas superficiais da Baía, hipótese que é corroborada por outros estudos realizados em sistemas semelhantes. ${ }^{24,25}$ Os fluxos médios de $\mathrm{N}_{2} \mathrm{O}$ na Baía, computados a partir das Equações propostas por Liss e Merlivat ${ }^{20}$ e Raymond e Cole ${ }^{23}$ para o cálculo das velocidades de transferência $\left(k_{\mathrm{w}}\right)$ na interface ar-mar foram, respectivamente, $0,3 \mathrm{e}$ $3,1 \mu \mathrm{g} \mathrm{N} \mathrm{m}{ }^{-2} \mathrm{~h}^{-1}$. Estima-se, portanto, que a baía de Guanabara emita diariamente para a atmosfera de 2 a $23 \mathrm{~kg}$ de $\mathrm{N}$ sob a forma de $\mathrm{N}_{2} \mathrm{O}$. Essa diferença de uma ordem de grandeza se deve exclusivamente às diferentes equações utilizadas para o cálculo de $k_{\mathrm{w}}$. Considerando-se que a equação proposta por Raymond e Cole $^{23}$ para o cálculo de $k_{\mathrm{w}}$ seja a mais apropriada para a estimativa da troca de gases entre a atmosfera e águas fluviais e estuarinas, é admissível que a taxa de emissão de $\mathrm{N}_{2} \mathrm{O}$ das águas da Baía de Guanabara seja próxima ao limite superior estimado. Nesse caso, cerca de $0,02 \%$ do total de $\mathrm{N}$ lançado diariamente através dos rios na Baía de Guanabara (130-140 $t \mathrm{~N})^{32}$ são transferidos como $\mathrm{N}_{2} \mathrm{O}$ para a atmosfera nos limites geográficos compreendidos pela Baía. Essa relação entre a quantidade de $\mathrm{N}_{2} \mathrm{O}$ emitido e a de $\mathrm{N}$ total que entra na Baía por vias fluviais se assemelha àquela encontrada por Harrison et al..$^{26} \mathrm{em}$ canais e rios receptores de águas drenadas de campos agrícolas do Valle del Yaqui (México), que estimaram que $0,05 \%$ do total de $\mathrm{N}$ aplicado na agricultura foram emitidos para a atmosfera como $\mathrm{N}_{2} \mathrm{O}$ das superfícies dos rios e canais. Esses valores são, entretanto, inferiores à razão $(0,33 \%)$ entre a quantidade anual de $\mathrm{N}_{2} \mathrm{O}$ emitida de estuários $\left(3,3 \times 10^{3} t \mathrm{~N}\right) \mathrm{e}$ a quantidade de $\mathrm{N}$ inorgânico lançada pelos rios às águas do Atlântico Sul $\left(9,9 \times 10^{5} t \mathrm{~N}\right)$, estimada por Seitzinger e Kroeze. ${ }^{8}$ 


\section{AGRADECIMENTOS}

Ao Prof. E. D. Barbiére, do Departamento de Geoquímica da UFF, pela concessão dos dados meteorológicos, e ao CNPq pelo apoio financeiro concedido através dos Projetos 474113/2003-5 e 477073/2007-7.

\section{REFERÊNCIAS}

1. Hansen, J.; Sato, M.; Ruedy, R.; J. Geophys. Res. 1997, 102, 6831.

2. IPCC, Intergovernmental Panel on Climate Change; Climate Change 2001: The Scientific Basis: Contribution of Working Group I to the Third Assessment Report of the Intergovernmental Panel on Climate Change, New York, 2001.

3. Battle, M.; Bener, M.; Sowers, T.; Tans, P. P.; Butler, J. H.; Elkins, J. W.; Conway, T.; Zhang, N.; Lang, P.; Clarke, A. D.; Nature 1996, 383, 231.

4. Vitousek, P. M.; Aber, J. D.; Howarth, R. W.; Likens, G. E.; Matson, P. A.; Schindler, D. W.; Schlesinger, W. H.; Tilman, D. G.; Ecol. Appl. 1997, 7, 737.

5. Fenchel, T., Blackburn, T. H.; Bacteria and Mineral Cycling, Academic Press: London, 1979.

6. Wrage, N.; Velthof, G. L.; van Beusichem, M. L.; Oenema, O.; Soil Biol. Biochem. 2001, 33, 1723.

7. Seitzinger, S. P.; Limnol. Oceanogr. 1988, 33, 702.

8. Seitzinger, S. P.; Kroeze, C.; Global Biogeochem. Cycles 1998, 12, 93.

9. Guimarães, G. P.; de Mello, W. Z.; Quim. Nova 2006, 29, 54.

10. JICA, Japan Internation Cooperation Agency Kokusai Kogyo Co. Ltd.; The Study on Recuperation of the Guanabara Bay Ecossystem - Sumary, Rio de Janeiro, 1994.

11. Valentin, J.; Tenenbaum, D.; Bonecker, A.; Bonecker, S.; Nogueira, C.; Paranhos, R.; Villac, M. -C.; J. Rec. Océanographique 1999, 24, 33.

12. Kjerfve, B.; Ribeiro, C. H. A.; Dias, G. T. M.; Filipo, A. M.; Quaresma, V. S.; Cont. Shelf Res. 1997, 17, 1609.

13. CIDS - Centro Internacional de Desenvolvimento Sustentável; Baía de Guanabara - Dossiê Sócio-Ambiental, Rio de Janeiro, 2000.
14. Amador, E. D. S.; Baía de Guanabara e Ecossistemas Periféricos: Homem e Natureza, Edição do autor: Rio de Janeiro, 1997.

15. Weiss, R. F.; Price, B. A.; Mar. Chem. 1980, 8, 347.

16. Grasshoff, K. M.; Ehrhardt, K.; Kremling, K.; Methods of Seawater Analysis, Deerfeld Beach: Florida, 1983.

17. Eaton, A. D.; Clesceri, L. S.; Greenberg, A. E.; Standard Methods for the Examination of Water and Wastewater, American Public Health Association: Washington, 1995.

18. Liss, P. S.; Slater, P. G.; Science 1974, 247, 181.

19. Broecker, W. S.; Peng, T.-H.; Tellus 1974, 26, 21.

20. Liss, P. S.; Merlivat, L. Em The Role of Air-Sea Exchange in Geochemical Cycling; Buat-Ménard, P., ed.; D. Reidel Publishing Company: Dordrecht, 1986.

21. Wanninkhof, R.; J. Geophys. Res. 1992, 97, 7373.

22. Clark, J. F.; Schlosser, P.; Simpson, H. J.; Stute, M.; Wanninkhof, R.; Ho, D. T. Em Air-Water Gas Transfer; Jähne, B.; Monahan, E. C., eds.; AEON Verlag \& Studio: Hanau, 1995.

23. Raymond, P. A.; Cole, J. J.; Estuaries 2001, 24, 312.

24. Hashimoto, S.; Gojo, K.; Hikota, S.; Sendai, N.; Otsuki, A.; Mar. Environ. Res. 1999, 47, 213.

25. Zhang, A.; Zhang, J.; Xu, J.; Zhang, F.; Estuarine, Coastal and Shelf Science 2006, 68, 557.

26. Harrison, J.; Matson, P.; Global Biogeochem. Cycles 2003, 17, 1080, doi:10.1029/2002GB001991.

27. Couto, V. B.; Monografia de Bacharelado, Universidade Federal Fluminense, Brasil, 2006.

28. Nevison, C. D.; Weiss, R. F.; Erickson III, D. J.; J. Geophys. Res. 1995, 100, 15809 .

29. Morell, J. M.; Capella, J.; Mercado, A.; Bauza, J.; Corredor, J. E.; Mar. Chem. 2001, 74, 131.

30. Oudot, C.; Jean-Baptiste, P.; Fourré, E.; Mormiche, C.; Guevel, M.; Ternon, J.; Le Corre, P.; Deep-Sea Res. I 2002, 49, 1175.

31. Goreau, T. J.; Kaplan, W. A.; Wofsy, S. C.; McElroy, M. B.; Valois, F. W.; Watson, S. W.; Appl. Environ. Microbiol. 1980, 40, 526.

32. JICA - Japan International Cooperation Agency; The Study on Recuperation of the Guanabara Bay Ecossystem, Kokusai Kogyo, 1994. 